\title{
Optimization of Centrifugal Pump Impeller Outlet Vane Angle by Using Modal Analysis
}

\author{
Kotakar Sandeep Gulabrao ${ }^{1}$, D. S. Khedekar ${ }^{2}$ \\ ${ }^{1}$ JNEC, Department of Mechanical Engineering, Aurangabad (M.S), India \\ ${ }^{2}$ Professor, JNEC, Department of Mechanical Engineering, Aurangabad (M.S), India
}

\begin{abstract}
Hydraulic machine are used in daily life for industrial, farming and much more wide applications. When it is used for various applications that time various working conditions of body itself affect on performance of pump as well as the life of the pump. When we minimize the pumps vibration then it will directly or indirectly improve the performance and life of machine. For that purpose vibration of pump body minimization is very important. In this paper vibration of pump minimize by changing the centrifugal pump impeller outlet vane angle. Initially published two paper shows designing the pump impeller with new angle system, CATIA part analysis in ANSYS workbench which finds out 6 mode of natural frequency of vibration. Here it is shown experimental Result and FFT analysis result of new pumping systems. Which shown Vibration minimize, Performance increasing and mathematically shown life improvement
\end{abstract}

Keywords: Pump Vibration, FFT analysis, Impeller, pump Performance

\section{Introduction}

Vibration will exist in all pumps and indeed all rotating machines. It is unavoidable, and not a problem in itself: Pump designers design machines to withstand normal vibration limits. These limits vary by pump type, mounting configuration, power requirements, rotative speed and fluid being pumped. Typically, vibration goes largely ignored until it results in a symptomatic issue. Excessive vibration may lead to excessive noise, equipment damage, and premature fatigue failure. Developments in recent years such as BAC net, SCADA systems, and other building management systems and manufacturer designed and developed systems frequently measure and record vibration in pumps. Developing a benchmark reference, establishing limits, and incorporating vibration measurement as part of any preventative maintenance program will often allow pump service before vibration causes catastrophic failure or other unacceptable results. Yet vibration itself is not the "root problem": It is caused by something, either internally in the pump or within the system. Other thing is that Impeller outlet vane angle very high speed pump out the fluid. When this fluid pump out from impeller, outlet shape of impeller effect on the fluid outlet from impeller. Hence when pump design it should be always remember that fluid discharge from impeller should be created low shock waves inside the casing. Because this shocking waves create jerk inside the continuous flow systems which minimizing NPSH generation and effect on flow. This also minimizes the pump performance.

This paper detail study existing pump system and changing outlet vane angle create new systems. When design complete then these both systems experimentally studied and compare the result. What changess happens in new pumping system that's studied by experimentally, note down the vibration effect on performance and life of pump.

Despite the long history of literature documenting forces on pump impeller, there are few detailed investigations into the effects of various impeller and flow pattern. The fluidstructure interaction phenomenon is the main cause of flowinduced vibrations at the blade passing frequency in large and high pressure centrifugal pumps. One way to reduce the effects of this interaction and pump vibration is to increase the effective gap by cutting the blade exit of the impeller. However, this cut of the impeller blade will affect the pump head and the flow pattern inside the pump volute studied by Atia E. Khalifa(1).

Flow visualization shows the cause of seal failure to be pressure pulsation generated by collapsing cavitation zone studied cruid oil pipeline in saudi arebia by Ulrich bolleter, Diether Schwarz etal (2)

The sources of vibration in centrifugal pumps can be categorized into three types Mechanical causes, Hydraulic causes \& Peripheral causes and pump detail study by Sanjay Taneja (3)

The nature of the faults, symptoms shown within the pump that could be utilised for specific fault detection and diagnosis and any mechanical corrective procedures that exist to help alleviate the problem studied by Kristoffer K. McKee, Gareth Forbes etal(4)

The detection of the centrifugal pump impeller blades cracks using vibration analysis technique is investigated using both time and frequency domain methods by Waleed Abdulkarem etal (5)

Unsteady hydraulic forces, very likely associated with impeller discharge recirculation were eventully consider to produce the hydraulic excitation for high vibration studied by Bruno schiavello etal(6)

Modal analysis of Centrifugal pump impeller which shows structural deformation minimum and natural frequency find out by Sandeep Kotakar and prof. Khedekar (7) 


\section{International Journal of Science and Research (IJSR) \\ ISSN (Online): 2319-7064}

Index Copernicus Value (2013): 6.14 | Impact Factor (2014): 5.611

\section{Vibrations in Centrifugal Pumps}

It is necessary to be interested in vibration in centrifugal pumps because it has a major effect on the performance. Generally, increasing vibration levels indicate a premature failure, which always means that the equipment has started to destroy itself. It is so because excessive vibrations are the outcome of some system malfunction. It is expected that all pumps will vibrate due to response from excitation forces, such as residual rotor unbalance, turbulent liquid flow, pressure pulsations, cavitation, and pump wear. The magnitude of the vibration will be amplified if the vibration frequency approaches the resonant frequency of a major pump, foundation and piping component. Generally higher vibration levels (amplitudes) are indicative of faults developing in mechanical equipment.

\section{A. New Pump Impeller Design}

Initially, study the existing (old) impeller pump systems find out performance, Exiting vibration frequency at $30^{\circ}$ Pump Impeller outlet vane angle. Experimentally find out the efficiency of old system

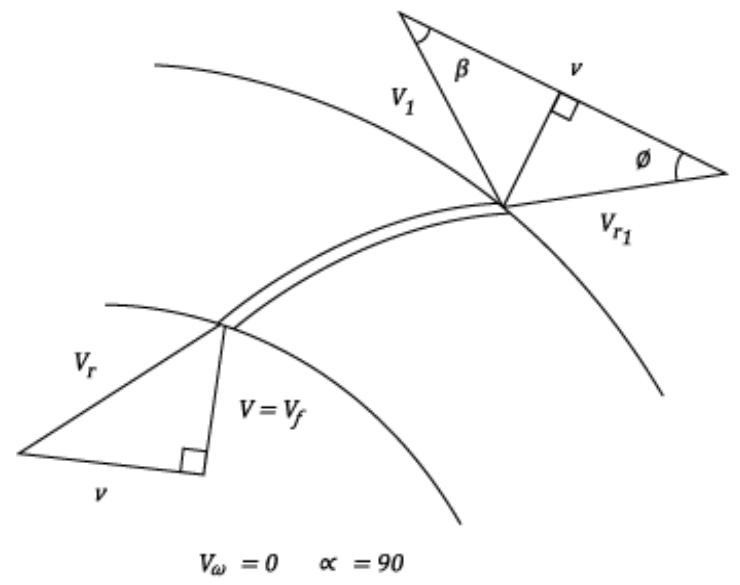

Figure 1: Centrifugal pump velocity triangle

\section{B. Overall efficiency of Centrifugal Pump}

Power input to the pump $=$ Power supplied to Electric motor $=$ Shaft power of Electric motor

$\boldsymbol{n}_{\text {overall }}=\frac{\mathrm{pgQH}_{\operatorname{mang}}}{\text { a7a0 }}$

$\boldsymbol{n}_{\text {overall }}=\boldsymbol{n}_{\text {mech }} \times \boldsymbol{n}_{\text {mano }}$

Now $n_{\text {mech }}=\frac{\rho \times Q \times V_{w 2} \times u_{2}}{\text { shaft porser }}$

Similarly $n_{\text {mano }}=\frac{g \times H_{m}}{v_{w 2} \times u_{2}}$

After detail study on old pump impeller systems along with FFT analysis, Design the pump impeller and pump systems as per requirement of company and changing the impeller outlet vane angle $20^{\circ}, 24^{\circ}, 30^{\circ}, 35^{\circ}$; generate CATIA part. This CATIA part save in igs file and import in Ansys workbench for Modal analysis. Find out the Natural frequency of vibration of impeller. From previous paper publication on software study of various degree, Natural frequency of vibration clear that all outlet vane angle of impeller have first natural frequency $0 \mathrm{~Hz}$ and second natural frequency is very high. So exiting frequency should be away from first natural frequency for avoiding vibration and resonance of pump systems. Then create impeller of pump from casting unit yogesh pump, Ahmednagar from Maximum effective new impeller system. That effective pump system is $24^{0}$ outlet vane angle impeller, which shows low structural deformation in modal analysis. When model generate and experimental test done on new impeller system pump that time FFT analysis done and find out exiting frequency of vibration. Comparing it with old pumping system FFT result, it is found that in case of new system exiting frequency far away from first natural frequency. So it minimizes resonance generation in pump system.

\section{Experimentally Find Out Efficiency}

The efficiency for $30^{\circ}$ blade vane angle is find out $41.2 \%$, for $24^{0}$ it was found that $42.4 \%$. This indicate that just changing the centrifugal pump outlet vane angle increase the performance. From this experimental result of performance and FFT result it is predict that resonance reduces and because of that efficiency goes on increasing. This is because of change the shock wave generation from $30^{\circ}$ to $24^{0}$. In $24^{0}$ water discharge occurs was smooth as compare to $30^{\circ}$ water discharge, this effect total performance of pump and also reduce vibration generation of pump. Hence assume when $5 \mathrm{Hp}$ pump run for $8 \mathrm{Hr}$ per day, as a vibration reduction increasing $1.2 \%$ efficiency of pump it save $1.2 \%$ power of $5 \mathrm{Hp}$ input power i.e.359Watt for a day, hence when it consider for 365days it save 131035 watt power save for one year. This type of saving occurs only changing the outlet vane angle, without any major change.

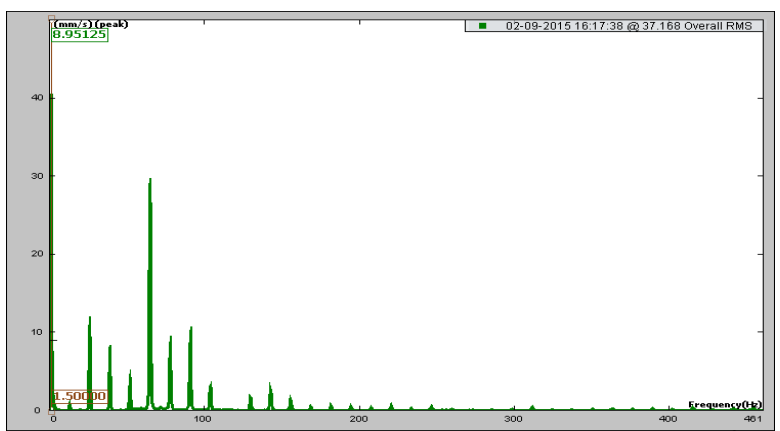

Figure 2: FFT result for old pumping systems $\left(30^{0}\right)$

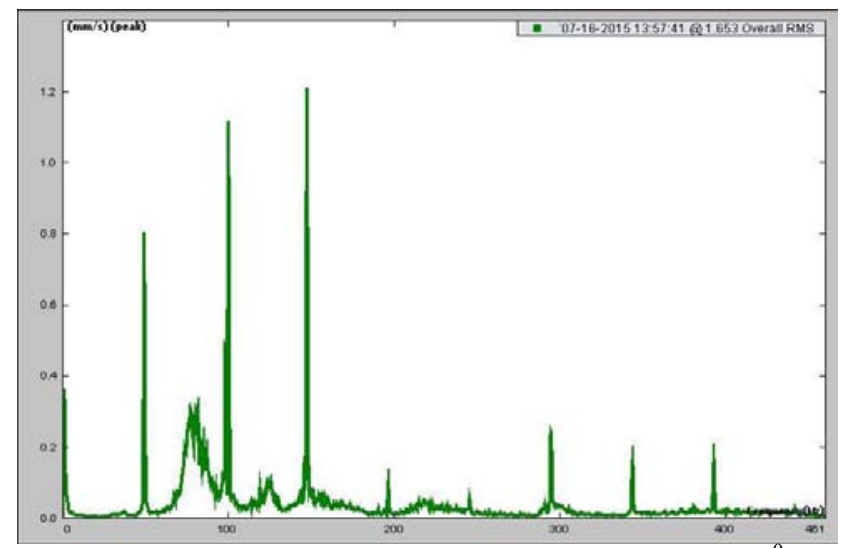

Figure 3: FFT result for new pumping systems $\left(24^{0}\right)$

\section{Vibration Effect on Pump Life}

When Pump is in working condition that time vibration of pump occurs certain limit. In our old pump system impeller outlet vane angle are $30^{\circ}$ that time first natural frequency $0 \mathrm{~Hz}$ and exciting frequency $60 \mathrm{~Hz}$ are close to each other because of that vibration resonance occurs. Because of 


\section{International Journal of Science and Research (IJSR) \\ ISSN (Online): 2319-7064}

Index Copernicus Value (2013): 6.14 | Impact Factor (2014): 5.611

resonance NPSC and bearing life minimize. When NPSH is minimize as compare to required NPSH it increase the cavitation problem of centrifugal pump impeller which reduce $\mathrm{H} \& \mathrm{Q}$ generation by pump which directly effect on the efficiency of pump.

Operating frequency: $\mathrm{f}=$ No of vanes $\times \frac{w}{2 \pi}$

$$
\begin{aligned}
& \mathrm{f}=\text { No of vanes } \times \frac{\frac{2 \pi \mathrm{N}}{60}}{2 \pi} \\
& \mathrm{f}=\text { No of vanes } \times \frac{\mathbb{N}}{60}
\end{aligned}
$$

For old pump system, i.e. $30^{\circ}$ operating frequency from FFT

$$
\begin{gathered}
\text { result is } 60 \mathrm{~Hz} \\
\mathrm{f}=6 \times \frac{\mathbb{N}}{60}
\end{gathered}
$$$$
\mathrm{N}=600 \mathrm{Rpm}
$$

For this speed NPSH is $7.7 \mathrm{~m}$ of water

Similarly for new pump system i.e. $24^{0}$

$$
\mathrm{N}=1500 \text { Rpm }
$$

For this speed NPSH is $10 \mathrm{~m}$ of water head

Cavitation of impeller reduce the life of impeller and increase the noise and unbalance force on all parts. This unbalance force reduce the bearing life of pump and bearing failure occurs. Because of bearing failure Prime mover i.e. Electric motor failure occurs

Vibration Forces are Vibration is a dynamic response to a dynamic force, and an increase in force is extremely detrimental to bearing life, then, we also know that an increase in vibration (which results from an increase in forces) produces a corresponding decrease in bearing life which can be calculated. Also, if we know the source of the vibration and can reduce or eliminate this force, then a subsequent increase in bearing life can be expected.

Rule: Excessive vibration $=$ excessive force $=$ a reduction in bearing life

\section{Result and Discussion}

From previous paper software result and Theoretical result it is conclude that $24^{0}$ pump impeller is most suitable for avoiding structural deformation of pump impeller. Experimentation result of $24^{0}$ pump impeller shows efficiency goes on increasing $1.2 \%$ and it considering comparatively efficiency increase $29.1 \%$. Optimization of pump outlet vane angle is from $30^{\circ}$ to $24^{\circ}$ occurs that is $20 \%$ optimization of outlet vane angle possible

\section{Conclusion}

1) We modify pump system by changing only impeller dimension without changing material properties

2) Developing Optimize Outlet vane angle of Centrifugal pump impeller improve overall efficiency as well as Manomatric efficiency with considerable minimizing pump vibration

3) Saving Electric power

4) Increasing Life of pump by minimization of cavitation and also increase the life of prime mover by reducing bearing failure

\section{Future Scope of Study}

Minimization of Cost of manufacturing of $24^{0}$ pump impeller by changing Iron casting material as a plastic reinforced material using which completely reduce corrosion problem and also with minimization of vibration problem and cavitation

\section{References}

[1] Atia E. Khalifa "Effect of Blade Exit Shape on Performance and Vibration of a Double Volute Centrifugal Pump" International Journal of Materials, Mechanics and Manufacturing, Vol. 2, No. 4, November 2014; This work was supported by King Fahd University of Petroleum \& Minerals, DOI 10.7763/IJMMM.2014.V2.139

[2] Brian carney, Ulrich bolleter, Diether Schwarz, Earl A. Gordon "solution to cavitation induced vibration problem in crude oil pipeline pump" proceeding of the eighth international pump user symposium

[3] Sanjay Taneja "Effect Of Unbalance On Performance Of Centrifugal Pump" International Journal Of Scientific \& Technology Research Volume 2, Issue 8, August 2013 ISSN 2277-8616

[4] Kristoffer K. McKee, Gareth Forbes, Ilyas Mazhar, Rodney Entwistle and Ian Howard "A review of major centrifugal pump failure modes with application to the water supply and sewerage industries" review of major centrifugal pump failure modes with application to the water supply and sewerage industries, in Asset Management Council (ed), ICOMS Asset Management Conference, May 16 2011. Gold Coast, QLD, Australia: Asset Management Council.

[5] Waleed Abdulkarem, Rajakannu Amuthakkannan, and Khalid F. Al-Raheem "Centrifugal Pump Impeller Crack Detection Using Vibration Analysis" $2^{\text {nd }}$ International Conference on Research in Science, Engineering and Technology (ICRSET'2014), March 21-22, 2014 Dubai (UAE); http://dx.doi.org/10.15242/IIE.E0314606

[6] Bruno schiavello and Giancarlo cicatelli "Vibration Field problem resolved with analytical diagnostics approach and innovative impeller design" proceeding of the Twenty Third international pump user symposium 2007

[7] Sandeep Gulabrao Kotakar and Prof D. S. Khedekar "Optimization of Centrifugal Pump Impeller Outlet Vane Angle by Using Modal Analysis" International Journal of Current Engineering and Technology (ISSN: 2277 4106) in Vol.5, No.2 (March/ April 2015) at page no. 1091-1095 